\title{
DIFFERENCE BETWEEN TARGET AND POST OPERATIVE REFRACTIVE ERROR FOLLOWING CONGENITAL CATARACT SURGERY IN PAEDIATRIC PATIENTS VISITING ARMED FORCES INSTITUTE OF OPHTHALMOLOGY
}

\author{
Mamoona Javaid, Hannan Masud \\ Armed Forces Institute of Ophthalmology/National University of Medical Sciences (NUMS) Rawalpindi Pakistan
}

\begin{abstract}
Objective: To determine the difference between target and postoperative refraction in children with congenital cataract.

Study Design: Prospective interventional study.

Place and Duration of Study: This study was conducted at Armed Forces Institute of Ophthalmology (AFIO), Rawalpindi, from May 2017 to May 2018.

Methodology: This study was conducted on 38 eyes suffering from congenital cataract. Age at the time of surgery, axial length, average keratometry reading, estimated refraction, and the power of IOL implanted were recorded. Spherical equivalent of post-op refraction at 3 months after surgery was noted. The difference between the estimated and actual postoperative refraction was termed as prediction error. Age, keratometry, and axial length were then assessed for its effects on prediction error.

Results: Overall the mean prediction error was $1.43 \pm 1.98 \mathrm{D}$. The mean prediction errors in eyes with axial lengths $\geq 20 \mathrm{~mm}$ were $0.96 \pm 1.03 \mathrm{D}$ and in eyes $<20 \mathrm{~mm}$ were $5.50 \pm 3.49 \mathrm{D}$. The mean prediction errors in eyes in children aged $\geq 4$ years were $0.14 \pm 0.61 \mathrm{D}$ ) and in children aged $<4$ years was $2.60 \pm 2.07 \mathrm{D}$. The differences between the prediction errors for both axial length and age were statistically significant $(p<0.05)$.

Conclusion: IOL power calculations in eyes with axial length less than $20 \mathrm{~mm}$ and children less than 4 years of age are prone to postoperative refractive errors. This study has reflected that adult based formulas are not reliable in pediatric age group.
\end{abstract}

Keywords: Axial length, Cataract surgery, Congenital cataract, K readings, Myopic shift and prediction errors.

This is an Open Access article distributed under the terms of the Creative Commons Attribution License (http://creativecommons.org/licenses/by/4.0), which permits unrestricted use, distribution, and reproduction in any medium, provided the original work is properly cited.

\section{INTRODUCTION}

One of the major causes of blindness in paediatric age group which can easily be prevented is congenital cataract ${ }^{1}$. It affects approximately 200,000 children worldwide, with an estimated prevalence ranging from three to six per 10,000 live births ${ }^{1}$, which accounts for $12 \%$ (range: $7 \%$ $20 \%$ ) of preventable blindness ${ }^{2,3}$. Therefore it is extremely important to diagnose and manage it appropriately in childhood to decrease the visual handicap ${ }^{2,3}$. This requires early surgical removal of opaque lens and early post-op visual rehabilitation through accurate calculation of postoperative refractive error ${ }^{1-3}$.

Errors in calculating accurate IOL power and predicting post-operative refraction can lead

Correspondence: Dr Mamoona Javaid, Dept of Ophthalmology, Armed Forces Institute of Ophthalmology, Rawalpindi Pakistan Received: 08 May 2020; revised received: 11 Jun 2020; accepted: 17 Jun 2020 to amblyopia 4 . It is therefore, extremely necessary that we try to minimize such errors and try to calculate an accurate post-operative refractive error ${ }^{4}$. Several factors contribute to postoperative refractive error in paediatric population ${ }^{4}$. These include loss of accommodation, inaccurate biometry techniques for children and use of IOL power formulas which were essentially developed for adults 5 . Paediatric eyes are expected to behave differently compared to the adult eyes owing to postoperative growth in the size of the eyeball ${ }^{6}$. Resultantly, refractive changes are greatly influenced by changes in axial length and corneal curvature during early developmental years ${ }^{6}$. With an IOL of constant power implanted in the eyes, there exists a higher possibility of myopic shift in paediatric pseudophakes ${ }^{6}$. Therefore an under correction is usually planned at the time of surgery to cater for myopic shift ${ }^{5,6}$. 
Difference between target and post-operative refraction can occur due to any of the above factors. In our study we tried to focus on the association between axial length, $\mathrm{K}$ readings and age at time of surgery on post-operative refraction.

\section{METHODOLOGY}

Thirty eight eyes of 23 children under went cataract surgery. Patients who had a co-existing organic ocular or systemic defects were excluded. Children below 2 years and above 8 years of age and those with traumatic cataract were also excluded from the group.

Pre-operative assessment including detailed history, slit lamp biomicroscopy (for elder children) and fundus examination was performed. Axial length and keratometry readings were taken using hand-held keratometer and ultrasound based A-scan biometry machine of Nidek company, under anesthesia. SRK T formula was used to calculate the IOL power. While calculating IOL power myopic shift was taken into account and all children were under corrected according to their age.

Surgical decision was made according to the age of patient. For children 2-5 years of age; lensectomy, posterior capsulotomy, anterior vitrectomy and IOL implantation was done. For 5-8 years of children lensectomy, posterior capsulotomy and IOL implantation was done. Multipiece IOL was implanted in all cases receiving IOL. Wound closure was performed using 10/0 nylon sutures. All patients were prescribed topical steroids and antibiotics to prevent inflammation and infection. Cycloplegic eye drops were prescribed to prevent posterior synechie.

The age at the time of cataract surgery, power of the IOL implanted, axial length, K readings and the estimated postoperative refraction were recorded. Refraction was performed 3 months after surgery by a trained refractionist. Absorbable corneal sutures dissolved during these 3 months and stabilized corneal astigmatism. Spherical equivalent was calculated for cylindrical measurements. The difference between the estimated and actual postoperative refraction was then calculated and termed as prediction error. The data was then assessed to study the effects of axial length, keratometry, and age at the time of surgery on the accuracy of IOL power calculation.

\section{RESULTS}

Out of 23 children selected, 18 were male and 5 female (fig-1). Eight children had unilateral

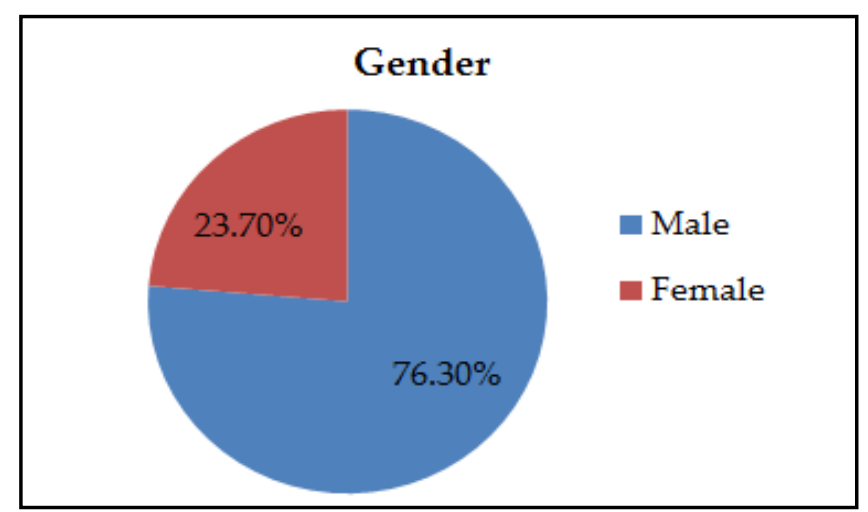

Figure: Study demographics.

cataract and 15 had bilateral cataract. Out of 38 eyes operated 20 were less than 4 years old and 18 were greater than 4 years old (table-I).

Axial length ranged from $18.64 \mathrm{~mm}$ to 24.00

Table-I: Demographic profile of patients $(n=38)$.

\begin{tabular}{l|c}
\hline Characteristic & Studied Eyes \\
\hline Age (years) & $4.86 \pm 2.27$ \\
$<4$ years & $20(52.6 \%)$ \\
$\geq 4$ years & $18(47.4 \%)$ \\
\hline Gender & \\
\hline Male & $29(76.3 \%)$ \\
Female & $9(23.7 \%)$ \\
\hline
\end{tabular}

Table-II: Descriptive statistics for various study parameters $(n=38)$.

\begin{tabular}{l|c}
\hline Parameter & Studied Children \\
\hline Axial Length (mm) & $21.97 \pm 1.58$ \\
$<20 \mathrm{~mm}$ & $4(10.5 \%)$ \\
$>20 \mathrm{~mm}$ & $34(89.5 \%)$ \\
\hline K Reading (Diopters) & $41.89 \pm 1.31$ \\
<41 diopters & $5(13.2 \%)$ \\
$41-42$ diopters & $23(60.5 \%)$ \\
$>42$ diopters & $10(26.3 \%)$ \\
\hline IOL Power & $26.55 \pm 3.93$ \\
\hline Prediction Error (diopters) & $1.43 \pm 1.98$ \\
\hline
\end{tabular}

$\mathrm{mm}$ with a mean of $21.97 \pm 1.58 \mathrm{~mm}$ while the keratometry readings ranged from $37.80 \mathrm{D}$ to 45.00 diopters with a mean of $41.89 \pm 1.31$ dio- 
Table-III: Stratification of mean prediction error (Diopters) across various subgroups $(n=38)$.

\begin{tabular}{|c|c|c|}
\hline Parameter & $\begin{array}{l}\text { Prediction Error } \\
(\text { Mean } \pm \text { SD) }\end{array}$ & $p$-value \\
\hline \multicolumn{3}{|l|}{ Age (Years) } \\
\hline$<4$ years & $2.60 \pm 2.07$ & \multirow{2}{*}{$<0.001^{*}$} \\
\hline$\geq 4 \mathrm{~mm}$ & $0.14 \pm 0.61$ & \\
\hline \multicolumn{3}{|c|}{ Axial Length (mm) } \\
\hline$<20 \mathrm{~mm}$ & $5.50 \pm 3.49$ & \multirow{2}{*}{$<0.001^{*}$} \\
\hline$>20 \mathrm{~mm}$ & $0.96 \pm 1.03$ & \\
\hline \multicolumn{3}{|c|}{ K Reading (diopters) } \\
\hline$<41$ diopters & $3.10 \pm 3.36$ & \multirow{3}{*}{$0.004 \sim$} \\
\hline 41-42 diopters & $1.74 \pm 1.61$ & \\
\hline$>42$ diopters & $-0.10 \pm 0.66$ & \\
\hline
\end{tabular}

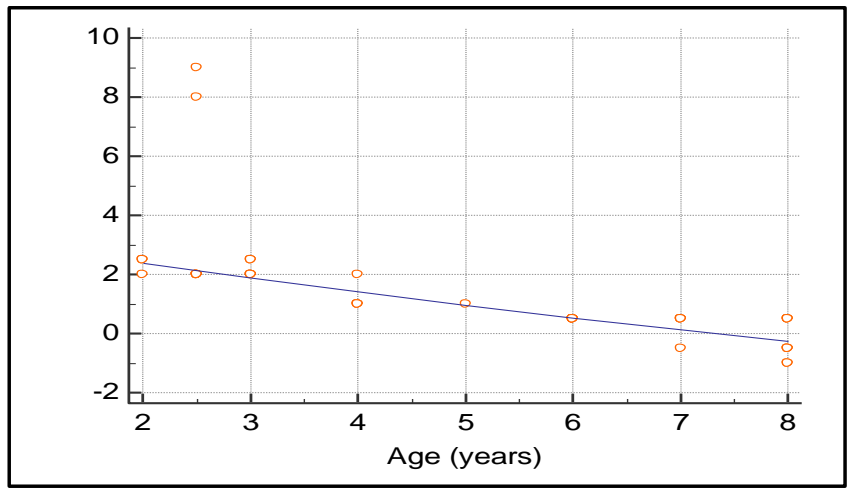

Figure-2: Prediction errors with age in eyes.

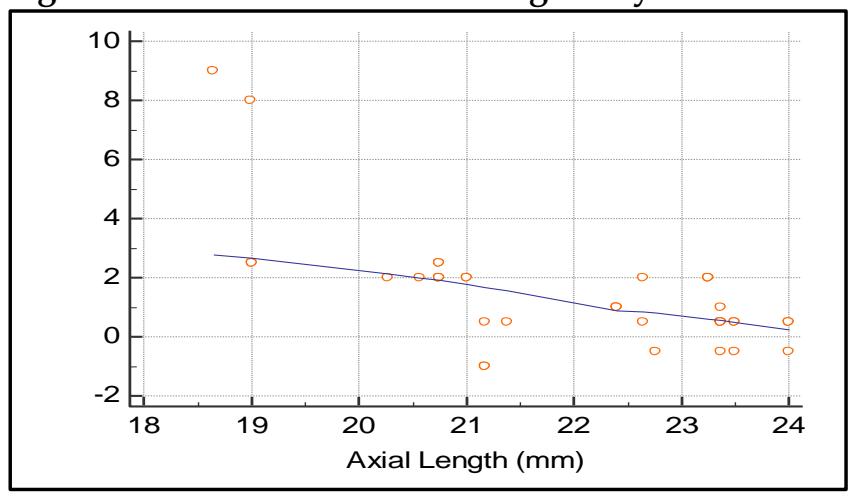

Figure-3: Prediction errors with axial length in eyes.

pters. The IOL power ranged from 23.00 to 38.00 with a mean of $26.55 \pm 3.93$. Overall prediction error ranged from -1.00 diopters to 9.00 diopters with a mean of $1.43 \pm 1.98$ diopters as shown in table-II.

Prediction error was significantly greater $(p-$ value $<0.001)$ in eyes with axial lengths $<20 \mathrm{~mm}$ and in children $<4$ years of age at the time of sur- gery. There was a trend towards greater prediction error in eyes with average $\mathrm{K}$ readings $<41$ Diopters as shown in table-III and fig- 2 \& 3 .

\section{DISCUSSION}

Calculation of accurate postoperative refractive error after paediatric cataract surgery is very difficult. Multiple factors that contribute to this unreliability include errors and difficulty in biometry techniques in paediatric age group ${ }^{3}$, different surgical techniques ${ }^{7}$, selection of IOL material, place of IOL insertion in eye, status of fellow eye1, family history of refractive errors and rate of growth of eye ball after surgery ${ }^{8}$.

The growth pattern in most children involves increase in axial length from $16.5 \mathrm{~mm}$ at birth to $23.6 \mathrm{~mm}$ in adults. Maximum part of this axial elongation takes place in first 2 years after birth. Eyeball continues to elongate even after that but the rate is comparatively slow ${ }^{9}$. Similarly, corneal curvature changes from $51.2 \mathrm{D}$ in newborns to $43.5 \mathrm{D}$ in adults ${ }^{10}$. This rapid transition in eye growth is a major factor for difference in target and postoperative refraction.

A greater myopic shift is noted in children who undergo surgery during first 2 years of life as compared to elder children, which was estimated to be around ${ }^{10}$ diopters ${ }^{11}$. Medsinge et al states that a higher prediction error is seen in children under 2 years of age due to smaller axial lengths, changes in corneal curvature and shallow anterior chambers ${ }^{1}$. In Infant Aphakia Treatment Study, refractive changes at 5 years of age were observed for children who had cataract extraction along with IOL implantation ${ }^{12,13}$. It showed that during the first 1.5 years of life, myopic shift was greatest ${ }^{12,13}$. This makes calculating IOL power in early years of child's life extremely difficult, leading to higher prediction errors. The rate of myopic shift declines with increase in child's age. It is $-1.00 \mathrm{D}$ if the surgery is performed at age 11 years to 14 years of age ${ }^{14}$.

Difficulty in performing biometry in children and using IOL formulas that were originally designed for adult population further complicate intra-ocular lens power calculation. Also children 
are unable to fixate properly so biometry is performed under anaesthesia. Errors in biometry can also result from human error as there is a learning curve associated with it. Most common techniques used for biometry are contact and immersion A scan biometry. Trivedi et al showed that contact biometry and immersion. A scan biometry give significantly different postoperative refraction outcomes in children ${ }^{15}$. Jianbing et al showed that formula with least predictability in children was SRK II and with maximum predictability was Hoffer and Holladay 116. However Mustafa et al showed that formula with the best pediatric results and predictability was SRK /T. He also observed that shallower anterior chamber depth and higher mean absolute error had an association for all formulas except Holladay 117.

Surgical technique used in surgery also effects postoperative results. Majority of children are likely to develop posterior capsular opacification (PCO) if posterior capsule is left intact. Hence in younger children it is absolute necessary to perform primary posterior capsulotomy and anterior vitrectomy at the time of surgery. Similarly, optic capture of IOL can also decrease incidence of PCO1.

Another major factor for post-operative refraction inaccuracy is the age at which IOL should be implanted. In adult population if cataract surgery is delayed, the effect on visual outcomes is not as alarming as in paediatric population. Also if aphakia is not corrected immediately in adults, it cannot cause amblyopia in comparison to children. Delaying the cataract surgery in children and not correcting aphakia timely can have disastrous effects on child's final visual outcome even leading to blindness. There are two schools of thoughts regarding time of surgery and IOL implantation in children, one in favour of early IOL implantation and second against it. Nihalaani et al showed that after 4.5 years of follow-up, there was no visual advantage of implanting an IOL over a contact lens ${ }^{18}$. Also IOL implantation was associated with more intra-operative and post-operative complications ${ }^{18}$. Similarly, Lambert et al debates that in children under 6 months of age there is a higher incidence of visual axis opacities with IOL implantation compared with aphakia ${ }^{19}$. Sefi et al emphasized optical rehabilitation through early correction of aphakia by either contact lenses or glasses to prevent the development of amblyopia ${ }^{20}$. Similarly, Koch et al and Tadros et al showed adequate results after secondary IOL implant in preschoolers ${ }^{21,22}$.

An important point to take into consideration is the fact that congenital cataract does not always occurs in isolation. It is commonly part of certain syndromes (micro-ophthalmia), infections, metabolic disorders or genetic mutations, which not only involve the lens but also affect other ocular structures responsible for optics of eye $^{23}$. Furthermore post-operative complications also alter the visual outcome. Most common complications of congenital cataract include PCO, glaucoma, pupil decentralization, squint and endophthalmitis. Retinal detachment has also been observed following congenital cataract extraction which requires a second surgery ${ }^{13}$. This makes the process of calculation of post-operative emmetropia even more complicated and unreliable.

\section{CONCLUSION}

IOL power calculations in eyes with axial length less than $20 \mathrm{~mm}$ and children less than 4 years of age are prone to postoperative refractive errors. This study has reflected that adult based formulas are not reliable in pediatric age group. Therefore, it is necessary to follow guidelines which comprehen-sively take into account all factors and yield a reliable and accurate postoperative refractive error.

\section{CONFLICT OF INTEREST}

This study has no conflict of interest to be declared by any author.

\section{REFERENCES}

1. Medsinge A, Nischal KK. Pediatric cataract: Challenges and future directions. ClinOphthalmol 2015; 9: 77-90

2. Gilbert C. Worldwide causes of blindness in children. In: Wilson ME, Saunders RA, Trivedi RH, editors. Pediatric Ophthalmology: Current Thought and a Practical Guide. Heidelberg, Germany: Springer; 2009; 47-60. 
3. Ganesh SC, Rao SG, Alam F. Pediatric intraocular lens power calculation. TNOA J Ophthalmic Sci Res 2018; 56: 232-36.

4. Nihalani B, Veen VD. Benchmarks for outcome indicators in pediatric cataract surgery. Eye 2017; 31(1): 417-21.

5. Mary C, Deborah KW. Vanderveen complications of pediatric cataract surgery. Seminars in Ophthalmol 2014; 29(1): 414-20.

6. Magli A, Forte R, Carelli R, Rombetto L, Magli G. Long-term outcomes of primary intraocular lens implantation for unilateral congenital cataract. Seminars Ophthalmol 2016; 31: 548-53.

7. Lin $\mathrm{H}, \mathrm{Tan} \mathrm{X}$, Lin Z. Capsular outcomes differ with capsulorhexis sizes after pediatric cataract surgery: a randomized controlled trial. Sci Rep 2015; 5: 16227.

8. Al Shamrani M, Al Turkmani S. Update of intraocular lens implantation in children. Saudi J Ophthalmol 2012; 26(3): 271-75.

9. Hussain RN, Shahid F, Woodruff G. Axial length in apparently normal pediatric eyes. Eur J Ophthalmol 2014; 24(1): 120-23.

10. Wilson ME, Trivedi RH. Choice of intraocular lens for pediatric cataract surgery: survey of AAPOS members. J Cataract Refract Surg 2007; 33(9): 1666-68.

11. Cornejo DAV, Boza AF. Relationship between preoperative axial length and myopic shift over 3 years after congenital cataract surgery with primary intraocular lens implantation at the National Institute of Ophthalmology of Peru, 2007-2011. Clin Ophthalmol 2018; 12(1): 395-99.

12. Weakley DR, Lynn MJ, Dubois L, Cotsonis G, Wilson ME, Buckley EG, et al. Myopic shift 5 years after intraocular lens implantation in the infant aphakia treatment study. Ophthalmol 2017; 124(1): 822-27.

13. Lim ME, Buckley EG, Prakalapakorn SG. Update on congenital cataract surgery management. Curr Opin Ophthalmol 2017; 28(1): 87-92.

14. Crouch ER, Crouch ER, Pressman SH. Prospective analysis of pediatric pseudophakia: Myopic shift and postoperative outcomes. J Pediatr Ophthalmol Strabismus 2002; 6(5): 277-82.

15. Trivedi RH,. Prediction error after pediatric cataract surgery with intraocular lens implantation: Contact versus immersion Ascan biometry. J Cataract Refract Surg 2011; 37(3): 501-05.

16. Li, J, Liu, Z, Wang R. Accuracy of intraocular lens power calculations in paediatric eyes. Clin Experiment Ophthalmol 2020; 258(1): 1123-31.

17. Mustafa MZ, Khan AA, Bennett $H$, Tatham AJ, Wright M. Accuracy of biometric formulae in hypermetropic patients undergoing cataract surgery. Eur J Ophthalmol 2019; 29(5): 510-15.

18. Nihalani BR. Congenital cataract; lessons learned from infant aphakia treatment study. Adv Ophthalmol Optom 2016; 1(1): 211-29.

19. Lambert SR, Aakalu VK, Hutchinson AK, Pineles SL, Galvin JA, Heidary G. Intraocular lens implantation during early childhood: a report by the american academy of ophthalmology. Ophthalmol 2019; 126(10): 1454-61.

20. Sefi-Yurdakul N, Berk AT. Primary and secondary intraocular lens implantations in children with pediatric cataract: visual acuity and strabismus at the age of 2 years and older. J Pediatr Ophthalmol Strabismus 2017; 54: 97-102.

21. Koch CR, Junior NK, Serra A, Morales M. Long-term results of secondary intraocular lens implantation in children under 30 months of age. Eye (Lond) 2018; 32(12): 1858-63.

22. Tadros D, Trivedi RH, Wilson ME. Primary versus secondary IOL implantation following removal of infantile unilateral congenital cataract: outcomes after at least 5 years. J AAPOS 2016; 20(1): 25-29.

23. Wu X, Long E, Lin H, Liu Y. Prevalence and epidemiological characteristics of congenital cataract: a systematic review and meta-analysis. Sci Rep 2016; 6(1): 28564. 